\title{
Novel pH-sensitive drug-loaded electrospun nanofibers based on regenerated keratin for local tumor chemotherapy
}

DOI:

10.1177/0040517520919920

\section{Document Version}

Accepted author manuscript

Link to publication record in Manchester Research Explorer

Citation for published version (APA):

Zhang, J., Li, J., Xu, C., Xi, Z., Ren, Y., Song, Q., \& Lu, S. (2020). Novel pH-sensitive drug-loaded electrospun nanofibers based on regenerated keratin for local tumor chemotherapy. Textile Research Journal.

https://doi.org/10.1177/0040517520919920

\section{Published in:}

Textile Research Journal

\section{Citing this paper}

Please note that where the full-text provided on Manchester Research Explorer is the Author Accepted Manuscript or Proof version this may differ from the final Published version. If citing, it is advised that you check and use the publisher's definitive version.

\section{General rights}

Copyright and moral rights for the publications made accessible in the Research Explorer are retained by the authors and/or other copyright owners and it is a condition of accessing publications that users recognise and abide by the legal requirements associated with these rights.

\section{Takedown policy}

If you believe that this document breaches copyright please refer to the University of Manchester's Takedown Procedures [http://man.ac.uk/04Y6Bo] or contact uml.scholarlycommunications@manchester.ac.uk providing relevant details, so we can investigate your claim.

\section{OPEN ACCESS}




\title{
Novel pH-sensitive drug-loaded electrospun nanofibers based on regenerated keratin for local tumor chemotherapy
}

Textile Research Journa $0(00) 1-14$

(C) The Author(s) 2020 Article reuse guidelines: sagepub.com/journals-permissions DOI: $10.1177 / 0040517520919920$ journals.sagepub.com/home/trj

SAGE

\author{
Jing Zhang' ${ }^{\circledR}$, Jiashen $\mathbf{L i}^{2}$, Chengshu $\mathbf{X u}^{\prime}$, Zhihua $\mathbf{X i}^{\prime}$, Yan Ren', \\ Qingwen Song' and Shaofeng Lu'
}

\begin{abstract}
The present work developed keratin-based $\mathrm{pH}$-sensitive nanofibers and explored the kinetics of the controlled-release effect. Extracted from wool fibers, keratin was firstly synthesized with 5- fluorouracil (5-FU). Then 5-FU/keratin was blended with poly (L-Lactide) PLLA solution and electrospun altogether to fabricate a nanofibrous scaffold, for local tumor chemotherapy. 5-FU/keratin/PLLA nanofibrous scaffolds were characterized by Fourier transform infrared spectroscopy to confirm that 5-FU was loaded within the nanofibers successfully. Scanning electron microscopy and transmission electron microscope images indicated the smooth and uniform structure of the nanofibers. Thermo-gravimetric analysis differential scanning calorimeter and X-ray diffraction techniques indicated 5-FU particles distributed in nanofibers at a molecular level. Compared with 5-FU from pure drug and 5-FU/PLLA nanofibers without keratin, the dissolution results indicated that 5- FU/keratin/PLLA nanofibers had a $\mathrm{pH}$-stimuli responsive character in the acidic environment. HCT-I 16 tumor cell line was applied to investigate the antitumor effect of the composite nanofibers. The MTS assay indicated that adding keratin into the system increased the inhabitation of tumor cells after 120 hours observation. Zeta potential analysis was introduced to analyze the interaction effect between 5-FU and keratin. The in vitro drug release kinetics analysis indicated that due to the electrostatic interaction between keratin and 5-FU molecules, the composite nanofibers can extend the release period of 5-FU in the acidic environment which suggested a longer effective inhibition in local tumor chemotherapy.
\end{abstract}

\section{Keywords}

composites, drug delivery, electrospinning, fabrication, fiber, yarn, fabric formation, materials

Tumor is a large, heterogeneous class of diseases in which clusters of cells display unlimited growth. ${ }^{1-3}$ Among the present clinical therapies, chemotherapy is considered as a major and effective method to inhibit and eliminate tumor cells. ${ }^{4-6}$ The mechanism of chemotherapy mainly aims to interrupt the tumor cell cycle, as well as the unlimited division process, then inducing tumor cell apoptosis. Unfortunately, in this process the adjacent healthy cells can be attacked by the chemotherapy drugs due to the serious toxic side effects. ${ }^{7,8}$ Moreover, many antitumor drugs have disadvantages during clinical applications; for example, they have poor water-solubility, they are easily metabolized and they exhibit plasma instability. ${ }^{9-12}$ [AQ1]As one of the oldest and the most commonly used anti-neoplastic drugs for colorectal cancer, 5-fluorouracil was restricted by the above problems. ${ }^{13}$ It is broadly applied in the treatment of various kinds of solid tumors, such as breast, colorectal and brain cancer. ${ }^{14}$ As a drug with

\footnotetext{
'Institute of Textiles and Clothing, Xi'an Polytechnic University, China

${ }^{2}$ School of Materials, University of Manchester, UK

Corresponding author:

Jing Zhang, The HK Polytechnic University Xi'an Polytechnic University, Jinhua south road 19\# Xi'an, ShaanXi 710048, China.

Email: jzhang@xpu.edu.cn
} 
short half-life period, 5-FU is metabolized rapidly within the human body and it is difficult to keep the effective concentration of 5-FU at a high enough level to maintain its therapeutic activity. Hence, continuous intravenous injection is necessary to keep a stable concentration of 5 -FU. ${ }^{15}$ There is a conflict that when 5 -FU is in plasma at a high concentration level, it has significantly toxic side-effects on normal tissue. ${ }^{16}$ On the other hand, the short half-life of 5-FU in plasma can hardly maintain an enduring therapeutic effect. In order to minimize the side-effects, a drug controlled-delivery system was developed accordingly to achieve a therapeutic effect with a controlled release profile over extended periods.

Proteins, as natural polymers, have aroused great interest as carriers for antitumor drug delivery for their excellent biodegradability and biocompatibility. As one member of the natural proteins, keratin was considered as a preferable candidate for chemotherapeutic drugs delivery because of its abundant active carboxyl groups and various amino terminals, which might play an important role in drug conjugation and drug encapsulation. As one of the most plentiful fibrous natural proteins, keratin can be found in feather, wool and animal claws. ${ }^{17,18}$ Keratins are a group of structural proteins composed of larger amounts of cysteine $(7-20 \%$ of the total amino acid residues) than other proteins. ${ }^{19}$ Also keratin possesses an intrinsic ability to self-assemble, and disulfide crosslinking of the thiol groups in keratin provides more possibilities for charges interaction and hydrogen bonds with drug molecules due to plentiful disulfide bonds in cysteine. ${ }^{20}$ Keratin derived from wool and human hair provides specific cellular binding motifs, such as leucine-aspartic acid-valine (LDV) and glutamic acid-aspartic acid-serine (EDS) binding residues, which are helpful in enhancing the cells attachments. In our previous study, it was found that keratin could be hydrolyzed into polypeptides chains with tailored amino acid terminal groups by adjusting the $\mathrm{pH}$ value of solvents for meshing the different isoelectric points. The selected keratin hydrolyzed polypeptides can be synthesized with different polymers. ${ }^{21}$

Electrospun nanofibrous scaffolds can be easily obtained from biodegradable synthetic polymers ${ }^{22-24}$ and natural polymers; ${ }^{25}$ both are preferable materials for tissue engineering, due to their ability to be tailored for the porosity, shapes and targeted functions of the native extracellular matrix $(\mathrm{ECM}) .{ }^{26-29}$ These microstructures within the electrospun fibers can help to encapsulate targeted drug models or other biologically active molecules. Therefore, electrospun nanofibers can be considered as potential candidates for drug delivery carriers. ${ }^{30}$

As one member of the synthetic aliphatic polyesters, $\operatorname{poly}(L$-lactide) (PLLA) was approved by the US Food and Drug Administration (FDA) for application in tissue engineering. ${ }^{31}$ The high porosity of PLLA fibrous structure provides potential possibilities for drug delivery. ${ }^{32}$ Moreover, PLLA nanofibers can be easily obtained because of the excellent spinnability by electrospun technology. However, due to its hydrophobic surface, the cellar affinities of PLLA cannot satisfy the requirements of biological evaluations. One solution is to modify the PLLA surface with hydrophilic molecules to improve its cellular attachments. ${ }^{33}$

In the previous study, it was noticed that the change of the nanofibrous system structure damaged the drug delivery effect since the diffusion situation could vary based on the structural changes. In the present study, an ethanol-replace procedure was applied accordingly to resolve this problem. Moreover, 5-fluorouracil was introduced as the targeted dug model. Since it is more effective when injected at a lower doses for a longer period of time, ${ }^{34,35}$ keratin was employed as the drug carrier to embed 5-FU small molecules. The controlledrelease of 5-FU was achieved by keratin gradually releasing from 5-FU-K-P composite nanofibers. Nanofibers of 5-FU-P and pure 5-FU were used as two control groups. The dissolution test indicted that 5-FU-P nanofibers did not possess controlled-release effect of 5-FU, nor pH sensitivity on the release profile of 5-FU. Moreover, the interaction binding between keratin and 5-FU was explored by Fourier-transform infrared spectroscopy (FTIR) and zeta potential analysis. The dissolution test investigated the drug controlled-release profile of 5-FU-K-P nanofibers and kinetics in different $\mathrm{pH}$ environments. The purpose of the present paper is to investigate the novel keratinbased biofunctional nanofibers which can be applied in a local antitumor drug delivery system.

\section{Materials and methods}

\section{Materials}

PLLA pellets (molecular weight of 200,000) were obtained from Hisun Pharmaceutical Co., Ltd (Taizhou, China). Chloroform was obtained from Sigma Aldrich Co., Ltd (USA); N, N-dimethyl formamide (DMF) was obtained from Hisun Pharmaceutical Co., Ltd (Taizhou, China). The wool fiber was collected from a factory in China. The drug model 5-fluorouracil (5-FU) was purchased from Sigma Chemicals Co., Ltd (Germany).

\section{Preparation of keratin wool-precipitates}

The wool fibers were immersed in $1 \mathrm{M} \mathrm{NaOH}$ solution which was kept thermostat in a water bath at $100^{\circ} \mathrm{C}$. [AQ2] After the wool fibers were dissolved thoroughly, 
the hydrolyzed solution was titrated to $\mathrm{pH} 5.55$ by hydrochloric acid. The hydrolyzate was filtered twice to remove the impurities. Then precipitates were collected by centrifuge in order to prevent granulations. Then precipitates were dispersed in aqueous solution again to remove ions and salts. Then the precipitates were dispersed in absolute ethanol to replace water in the system. The hydrolysis of keratin in an alkaline environment could cause the conversion of disulfide bonds to cystyl residues $\left(\mathrm{CyS}^{-}\right)$as explained in equation (1)

$$
2 \mathrm{CySSCy}+4 \mathrm{OH}^{-}=3 \mathrm{CyS}^{-}+\mathrm{CySO}_{2}^{-}
$$

\section{Preparation of drug-loaded nanofibers}

5-FU was added into keratin precipitates which were treated by ethanol. The compounds were kept at room temperature overnight. The reaction between 5-FU and keratin polypeptides with cysteine terminal was disrobed in Scheme 1. [AQ3]

5-FU powder was firstly added into the keratin precipitates. Then $10 \mathrm{wt} \%$ PLLA polymer was dissolved in a prepared organic solution with $90 \mathrm{wt} \%$ chloroform and $10 \mathrm{wt} \%$ DMF. The electrospun suspension was prepared by adding the $5-\mathrm{FU} /$ keratin composite into the PLLA solution. The suspension was filled into a syringe, which was connected with high voltage through a metal needle. The range of high voltage was from $15 \mathrm{kV}$ to $50 \mathrm{kV}$. The suspension was squeezed from the syringe by an air pump at a rate of $0.6 \mathrm{ml} / \mathrm{min}$. The distance between the metal needle and the grounded aluminum foil receptor was set as $15 \mathrm{~cm}$. Four types of nanofibers were electrospun: 5-FU/PLLA (5-FU-P) nanofibers, keratin/PLLA (K-P) nanofibers, 5-FU/keratin/PLLA (5FU-K-P) nanofibers and pure PLLA nanofibers.

\section{Morphology of keratin composite nanofibers}

The surface smoothness of the nanofibers was evaluated by scanning electron microscopy (SEM) (Quanta-450-FEG + X-MAX50, FEI Co., Ltd). The inner structures of the prepared nanofibers were evaluated by transmission electron microscope (TEM) (JEM-ARM200F-NEO ARM, JEOL Co., Ltd).

\section{Chemical structure analysis of the composite nanofibers}

The chemical bonds and interactions between drug model 5-FU, keratin and PLLA in the nanofibers were analyzed by FTIR. The scanning range was set from $4000 \mathrm{~cm}^{-1}$ to $500 \mathrm{~cm}^{-1}$ with a resolution of $2 \mathrm{~cm}^{-1}$ (Spotlight $400 \&$ Frontier, PerkinElmer). The transmission mode was selected for the test of

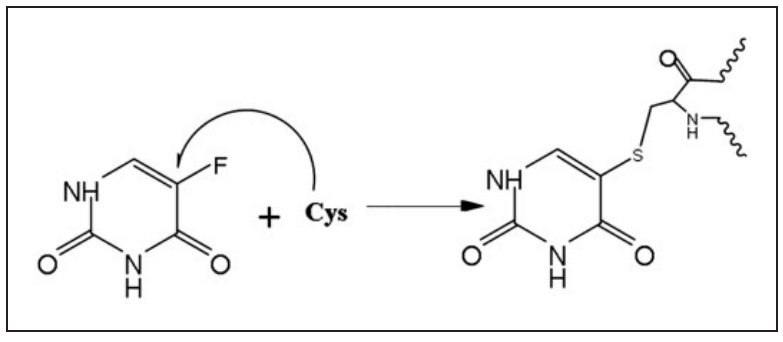

Scheme I. The substitution reaction between 5-FU and cysteine residue of keratin

nanofibers. The prepared electrospun samples were removed from the aluminum foil.

\section{Thermal properties of the composite nanofibers}

The thermo-gravimetric analysis/differential scanning calorimeter (NETZSCH STA449 F3) was applied in examination on thermal properties of the composite nanofibers. The prepared pure PLLA nanofibers, 5FU-P nanofibers, K-P nanofibers, 5-FU-K-P nanofibers and pure 5-FU powder were analyzed. The pure 5-FU was evaluated as a positive control and PLLA nanofibers were evaluated as a negative control.

\section{Zeta potential analysis}

Zeta potential analysis was introduced to investigate the interactions between 5-FU and keratin. The electric charges analysis and translational diffusion coefficient measurements were examined by a dynamic light scattering instrument (DT-300/310, DTI) at room temperature. Since ethanol was involved in the synthesis process of keratin alcohol precipitates, ethanol at analytical purity was selected as a dispersant agent. Then, $0.1 \mathrm{wt} \%$ keratin and keratin with 5-FU nanofibers were added and dispersed, respectively. The concentrations of electrospun composite nanofibers in ethanol were calculated by the system. The Smoluchowski equation (equation (2)) displays the factors that would influence the results of zeta potential analysis. ${ }^{36}$

$$
\zeta=\frac{d U}{d p} \times \frac{\eta}{\varepsilon \times \varepsilon_{0}} \times K
$$

Where $\zeta$ is the zeta potential, $d p$ is the pressure, $\eta$ is electrolyte viscosity, $K$ is electrolyte conductivity, $\varepsilon_{0}$ is the vide permittivity and $\varepsilon$ is the dielectric constant of electrolyte solution. [AQ4]

\section{Loading efficiency and in vitro $\mathrm{pH}$ sensitivity examination}

To identify the encapsulation efficiency and dosage of the composite nanofibers, $20 \mathrm{mg}$ of 5-FU loaded 
5-FU-K-P nanofibers and 5-FU-P nanofibers were dissolved in $10 \mathrm{~mL}$ of $\mathrm{DMF} /$ chloroform mixed solvent. Then $10 \mathrm{~mL}$ phosphate buffered saline (PBS) solution at $\mathrm{pH} 7.4$ was added and kept stirring for $1 \mathrm{~h}$ at room temperature. Until the complete evaporation of the organic phase, the mixture was centrifuged (5000 rpm) for $10 \mathrm{~min}$ to separate the aqueous phase. The concentration of 5-FU in PBS was examined by UV spectrophotometer. Equation (3) explains the drug-loading efficiency

Loading efficiency $(\%)=\frac{\text { residual drug in PBS }}{\text { initial drug amount }} \times 100 \%$

The prepared electrospun nanofibers were incubated in $500 \mathrm{ml}$ solution PBS at $\mathrm{pH}$ value of 7.4 with a constant temperature of $37.0^{\circ} \mathrm{C}$. The drug-loaded nanofibers with different compositions were immersed in $1000 \mathrm{ml}$ PBS at $37.0^{\circ} \mathrm{C}$. Hydrochloric acid and sodium hydroxide were applied to make PBS with preset $\mathrm{pH}$ values; $20 \mathrm{ml}$ PBS solution was collected and $20 \mathrm{ml}$ blank PBS solutions were filled into the bottles with samples for drug dissolution test at the preset interval. The incubated solution of blank nanofiber was used as a control. The concentrations of 5-FU in the collected solutions were evaluated by UV spectrophotometer at $265 \mathrm{~nm}$ and the calibration curve of 5-FU was calculated under the same experimental conditions. The solution of $\mathrm{pH} 6.0$ was applied in the same protocol based on the experimental conditions as described above. The drug release data was collected in the same experimental conditions as described above. The data collected in pH 7.4 PBS solution and pH 6.0 PBS solution were analyzed by Minitab and SPSS software. As shown in equation (4), the Korsmeyer-Peppas model was introduced to investigate the kinetics of the drug release profile.

$$
\frac{M_{t}}{M_{\infty}}=\partial \mathrm{t}^{n}
$$

Where $\partial$ is a constant incorporating structural and geometric characteristics of the drug dosage form, $\mathrm{n}$ is the release exponent.

\section{Antitumor activity by fluorescence images observation}

In order to observe the proliferation of cells, the HCT116 cell contained glass disks were also gently washed with PBS at $37^{\circ} \mathrm{C}$ and fixed with $4 \%$ paraformaldehyde in PBS at room temperature for $15 \mathrm{~min}$. Then the samples were permeabilized with $0.1 \%$ Triton X-100 in PBS for $5 \mathrm{~min}$ at room temperature. After that, the cells were incubated with $10 \mu \mathrm{g} / \mathrm{mL}$ TRICE-phalloidin in a dark environment for $30 \mathrm{~min}$ and the nucleuses of cells were additionally counterstained with $1 \mu \mathrm{g} / \mathrm{mL}$ DAPI in phosphate buffered saline. [AQ5] The proliferation on the surface of the glass disks was visualized by fluorescent Eclipse 80i (Nikon, Japan).

\section{Antitumor activity by MTS assay}

Cell toxicity test was investigated calorimetrically by assaying the uptake of 3-(4,5-dimethylthiazol-2-yl)-5(3-carboxymethoxyphenyl)-2-(4-sulfophenyl)-2H-tetrazolium (MTS) by the cells. HCT-116 cells were seeded into 24-well plates at a density of $1 \times 10^{4} / \mathrm{cm}^{2}$. Then the cells were cultured until they became confluent and incubated for $4 \mathrm{~h}, 24 \mathrm{~h}, 72 \mathrm{~h}$ and $120 \mathrm{~h}$. The collected cells were then detached, centrifuged and re-suspended into the medium containing $0.4 \%$ trypan blue (ThermoFisher, USA.). The cell numbers were counted by hemocytometer (HF-3800, China) and were normalized by that of the control group and expressed as a percentage of cell viability. HCT-116 cells were incubated at $37^{\circ} \mathrm{C} / 5 \% \mathrm{CO}_{2}$ in DMEM or RPMI 1640 medium with $10 \% \mathrm{FBS}$ and $100 \mathrm{IU} / \mathrm{mL}$ penicillin and $100 \mu \mathrm{g} / \mathrm{mL}$ streptomycin. HCT-116 cells were plated on 96-well plates for $24 \mathrm{~h}$ to reach $70 \%$ confluence $(5000$ cells, 10,000 cells/well, respectively). Cells were washed by PBS solution and incubated with either control culture medium or peptides-containing medium for $24 \mathrm{~h}$. Medium was removed and the cells were washed with fresh PBS; then $100 \mu 1$ fresh medium was added to each well. MTS solution was added to each well in the ratio of 1:5. The plates were incubated at $37^{\circ} \mathrm{C} / 5 \% \mathrm{CO}_{2}$ for $4 \mathrm{~h}$. Finally, OD values of the medium were examined at $492 \mathrm{~nm}$ using micro-plate reader. [AQ6]

\section{Results and discussion \\ Morphology of the composite nanofibers}

The composite fibers with interlaced network structures were fabricated by electrospinning technology. The diameters of the fibers were in the nano-scaled range. There are several factors influencing the morphologies and the spinnability: the solubility of the polymers, the applied voltage and the solution conductivity. While the metallic needle of the loaded syringe was applied with high voltage, a droplet of the polymer electrospun solution was squeezed at the end of spinneret. With more charges accumulated at the surface the droplet, a Taylor cone was formed and a polymer jet burst from the droplet surface. Under suitable conditions, the stream can be continuous and the solvent can evaporate rapidly during the spray of the polymer solutions. In the present study, smooth nanofibers with uniform 


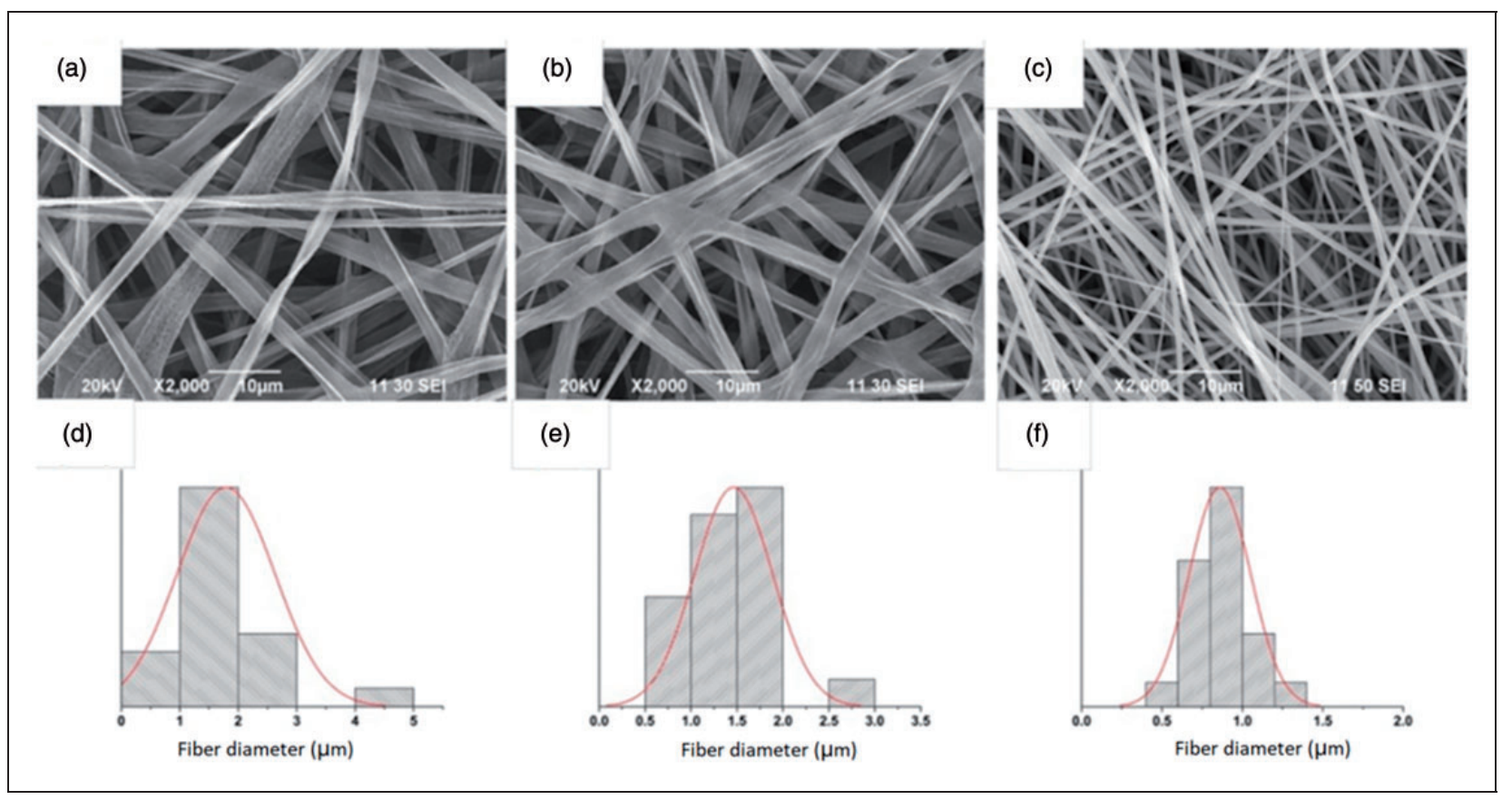

Figure I. Morphology of nanofibers and the fibrous diameter range: SEM images of (a) pure PLLA, (b) K-P, and (c) 5-FU-FU-K-P; normalized histogram of (d) pure PLLA, (e) K-P, (f) 5-FU-K-P. [AQ12] SEM: scanning electron microscope; PLLA: poly(L-lactide).

diameters in the range of $0.8-1.7 \mu \mathrm{m}$ were developed. Nanofibrous scaffolds were fabricated by collecting the randomly dispersed nanofibers on the flat receiver. Compared with bulk matter, nanofibrous scaffolds have the advantages of large surface area and high porosity. Unlike the synthetic polymers with preferable spinnability, the natural polymers nanofibers can be obtained under stringent conditions.

As shown in Figure 1, the microstructures of the measured composite nanofibers with different width values were highly correlated with their compositions. The spinnability of electrospinning can be enhanced by increasing the conductivity of the polymer solution by enlarging the repulsive voltage between the charges on the electrospun jet and the grounded receiver. [AQ7] The microstructures and morphologies of the nanofibers and scaffolds can be optimized by changing the parameters (e.g. the electrospun voltage, the concentration of electrospun solution). Based on adjusting the various parameters, the surface of modified keratinbased nanofibers can be seen in Figure 1. While the diameters of the different nanofibers maintained their nano-scale range, the surface smoothness slightly changed with the decrease of PLLA concentration. The surface of PLLA nanofibers was the smoothest out of the three samples. The SEM images show that there is no aggregation or accumulated beads within the microstructures of PLLA, K-P and 5-FUK-P nanofibers.
Unlike the smoothness, there are significant changes between the diameters of different composite nanofibers. By randomly measuring 100 nanofibers in the SEM images, the average diameter of pure PLLA nanofibers was calculated as $1.88 \pm 0.05 \mu \mathrm{m}$. The width of $\mathrm{K}$ $\mathrm{P}$ nanofibers reduced to $1.50 \pm 0.04 \mu \mathrm{m}$. The third sample of 5-FU-K-P nanofibers possessed an average diameter of $0.81 \pm 0.03 \mu \mathrm{m}$. Because the surface tension and viscosity of the solution can be improved by increasing the concentration of the polymer solution, a gradual increase in the diameter of the fibers was observed in Figure 1 due to the increased concentration of electrospun solution. Because of the significant decrease in concentration of PLLA after forming the tetra-component electrospun solution, the nanofibers became thinner and narrower.

The inner structure of nanofibers was characterized by TEM. The aim is to investigate the influence of the electrospun process on dispersion status of 5-FU, as well as that of keratin in the polymer matrix. The TEM images of the three kinds of samples are displayed in Figure 2: PLLA nanofibers, K-P nanofibers and 5FU-K-P nanofibers. In Figure 2(a), the structure of pure PLLA nanofiber can be seen. Figure 2(b) revealed the structure of K-P nanofibers. [AQ8] There are dispersed dark shadow areas surrounding the nanofibers, which was evidence of keratin existing amorphously in the composite nanofibers. Figure 2(c) displays the structure of drug-loaded nanofibers. It can be seen 


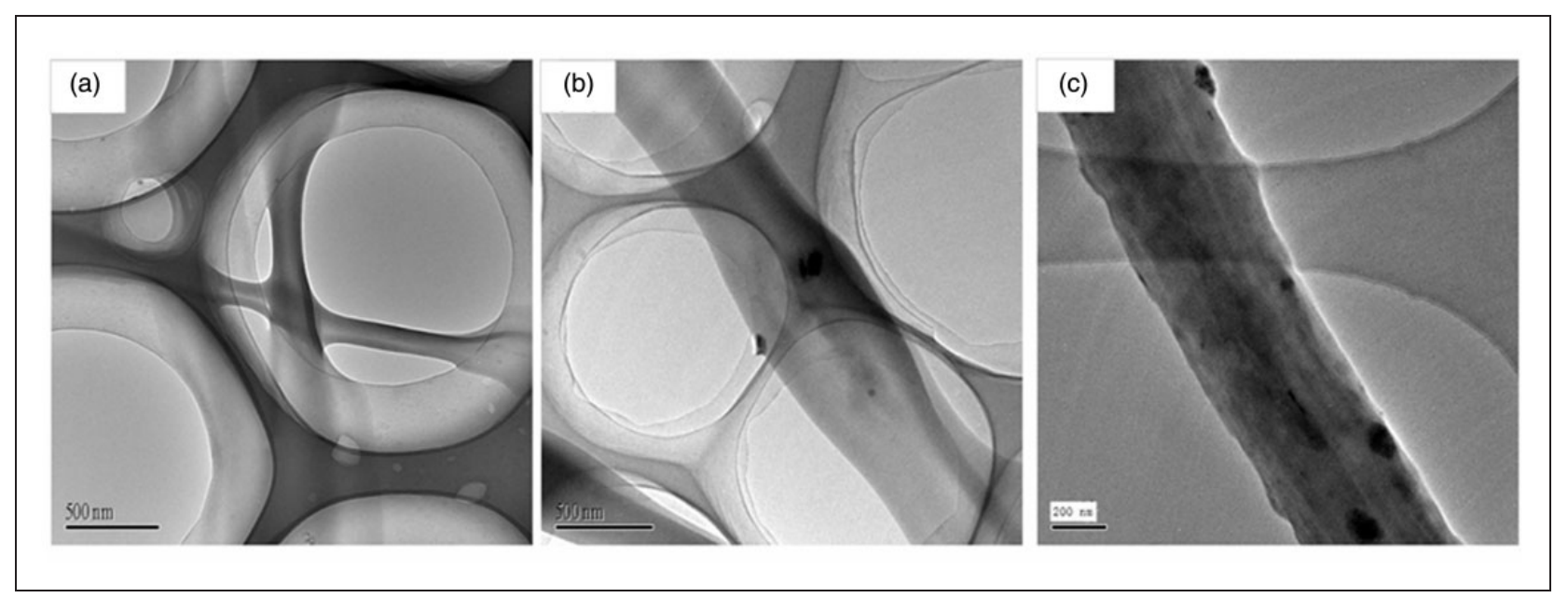

Figure 2. TEM images of (a) pure PLLA composite nanofiber; (b) K-P nanofiber; (c) 5-FU-K-P nanofiber. TEM: transmission electron microscope; PLLA: poly(L-lactide).

that the core of one single fiber is darker than its surface which suggested the density of the core part was greater than that of the surface part. The results of TEM images indicated that there are more 5-FU and keratin particles dispersing in the inner part of the drug-loaded nanofibers.

\section{Characterizations of the composite nanofibers}

The FTIR spectra of the electrospun nanofibers are shown in Figure 3(a). Spectra of 5-FU, 5-FU-P and $5-F U-K-P$ showed clusters of bands at $3250 \mathrm{~cm}^{-1}$, $1720 \mathrm{~cm}^{-1}$ and $1670 \mathrm{~cm}^{-1}$, which correspond to $\mathrm{N}-\mathrm{H}$ stretching, $\mathrm{C}=\mathrm{O}$ vibration and overlapping peaks of $-\mathrm{C}=\mathrm{O}$ and $-\mathrm{C}=\mathrm{C}$ vibrations. Those bands were believed to be the characteristic peaks of 5-FU molecules, which demonstrated the existence of 5-FU in the composite nanofibers. ${ }^{37}$ The results of FTIR spectra indicated that 5-FU was successfully loaded into the 5-FU-P nanofibers and 5-FU-K-P nanofibers. Moreover, it is clear that the high voltage of electrospun did not influence the chemical properties of the drug. [AQ9] Therefore the antitumor function of 5-FU was maintained during the whole fabrication procedure.

The characteristic peaks of keratin can also be observed in K-P nanofibers and 5-FU-K-P nanofibers. Amide bands represent various vibrational modes of the peptide bonds because proteins comprise amino acids linked by amide bonds. In Figure 3(a), two characteristic peaks of keratin were detected at 1630 and $1550 \mathrm{~cm}^{-1}$ which were attributed to amide I and II bands of keratin. The band at $1650 \mathrm{~cm}^{-1}$ corresponded to the $\alpha$-helix structure in keratin, while the bands in the range of 1631 to $1515 \mathrm{~cm}^{-1}$ were attributed to the $\beta$ sheet structure. The weak peaks related to the $\alpha$-helix structure suggested that the keratin conformation was more disordered. ${ }^{38}$

Thermal stability is a very important property for material use in biomedical applications. The TGA thermograms and differential thermal analysis (DTA) curves of 5-FU powder, PLLA nanofibers, 5-FU-P nanofibers and 5-FU-K-P nanofibers are shown in Figure 3(c) and (d). Three weight loss peaks were observed in the TGA curves. For the pure 5-FU sample, the maximum weight loss percentage was observed between 260 and $310^{\circ} \mathrm{C}$, with maximum degradation rate at $283.94^{\circ} \mathrm{C}$ which is probably associated with the decomposition of C-F bonds. For the 5FU-K-P samples, there's a broad peak at $230-270^{\circ} \mathrm{C}$ which was related to the thermal degradation of keratin and 5-FU. The byproduct deformation of PLLA during the heating process produced another peak appearing at $300-400^{\circ} \mathrm{C}$. For the 5-FU-P samples, the decomposition peak shifted to $320-350^{\circ} \mathrm{C}$. Because of the low weight ratio of the drug in the composite nanofibers, the characteristic peak of 5-FU was weaker than that of the pure drug. Figure 3 (d) displays a similar thermogram trend of differential curves. The results of TGA suggested that higher thermal stability can be achieved with a higher weight ratio of PLLA in the keratin/ PLLA electrospun nanofibers. One of the major peaks occurred at $295^{\circ} \mathrm{C}$ which is attributed to the thermal decomposition of 5-FU molecules. The second sharp peak at $345^{\circ} \mathrm{C}$ was probably initiated from chain scission of the ester linkage of PLLA. With the start of the PLLA thermal decomposition, the shielding layer was cracked and the encapsulated keratin with 5-FU was abruptly taken out simultaneously with PLLA decomposition, which might lead to mass loss with a slope higher than that of the pure PLLA nanofibers. From the results of TGA and DTG spectra, it can be 


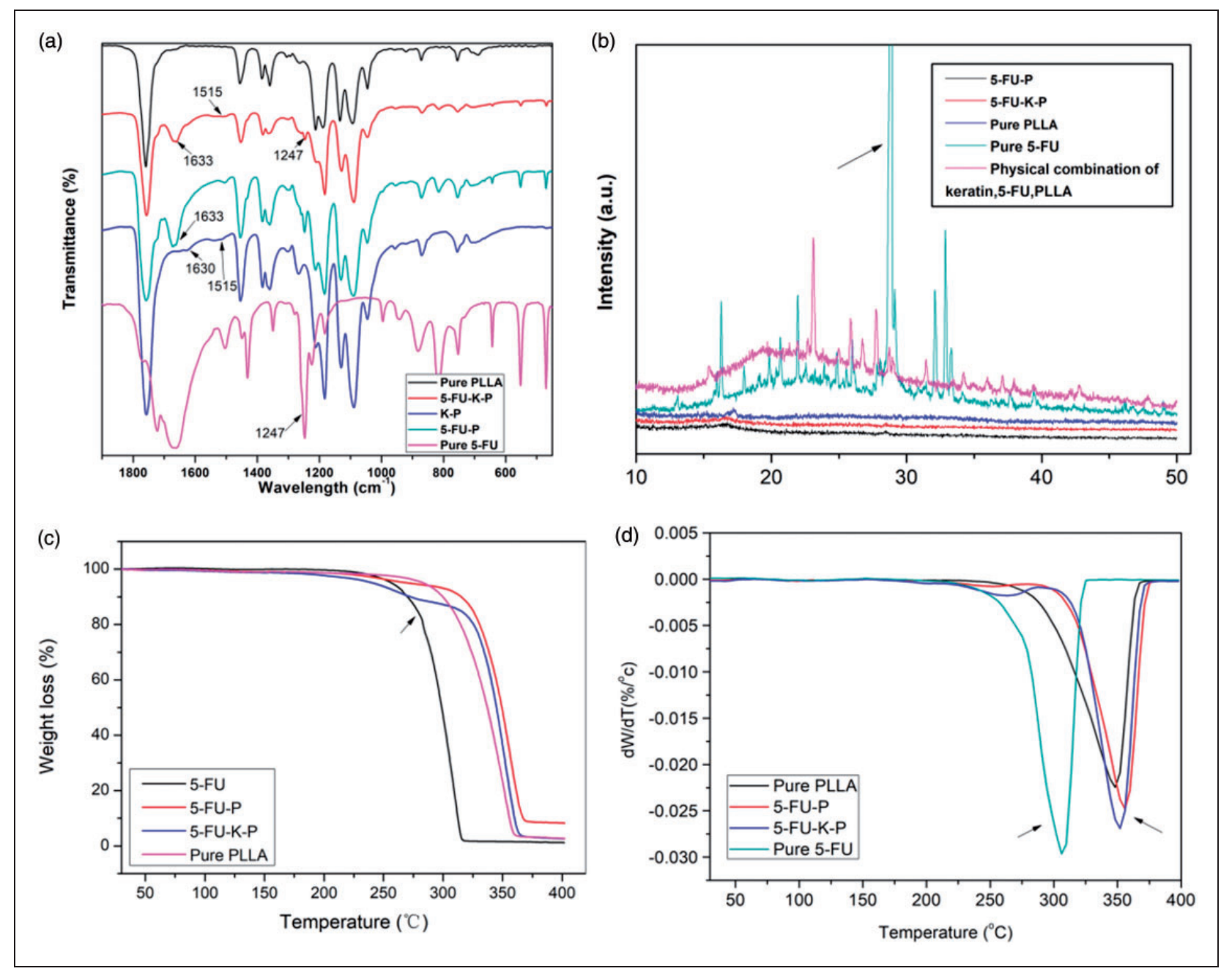

Figure 3. Characterizations of the composite nanofibers: (a) FTIR spectra; (b) XRD patterns; (c) TGA results; (d) DTA results. FTIR: Fourier transform infrared spectroscopy; XRD: X-ray diffraction; TGA: thermo-gravimetric analysis; DTA: differential thermal analysis; PLLA: poly(L-lactide).

concluded that the PLLA, working as a structural supporting material, can prevent thermal oxidation and decomposition of 5-FU. [AQ10] With more keratin existing in the composite drug-loaded nanofibers, more 5-FU was embedded by keratin intending to be in the core structure of the nanofibers which was observed in the previous TEM images.

The XRD spectra in Figure 3(b) illustrated the change of crystallites of PLLA nanofibers, 5-FU-P nanofibers, 5-FU-K-P nanofibers and 5-FU powder. Meanwhile, the physical mixtures of 5-FU powder, keratin powder and PLLA fibers were examined to compare how the electrospun process influenced the interactions between these three components. As shown in Figure 3(b), there are clusters of intense peaks at $16.2^{\circ}, 19.0^{\circ}, 20.5^{\circ}$ and $28.6^{\circ}$ which were assigned as the characteristic peaks of 5-FU. Those peaks suggested the typical crystalline structure of pristine 5-FU. ${ }^{34}$ The diffraction pattern of PLLA displayed a broad peak at $17.2^{\circ}$ in Figure $3(\mathrm{~b})$ which indicated the amorphous phase of the polymer. In order to explore the crystalline transformation during the electrospun process, the physical mixtures of 5-FU powder, keratin powder and PLLA fibers were investigated to make a comparison with 5-FU-K-P electrospun nanofibers. The characteristic peaks of 5-FU still can be observed for the physical mixed samples. However, the peaks significantly weakened in both 5-FU-P nanofibers and 5-FU-K-P nanofibers. The results demonstrated that the crystallinity of 5-FU decreased dramatically after being electrospun. The crystal structure of 5-FU powder shifted to a more amorphous structure of 5-FU-loaded nanofibers. There was no characteristic peak of 5-FU in either 5-FU-P nanofibers or 5-FU-K-P nanofibers. The absence of a peak indicated that the crystal structure of $5-\mathrm{FU}$ was not 


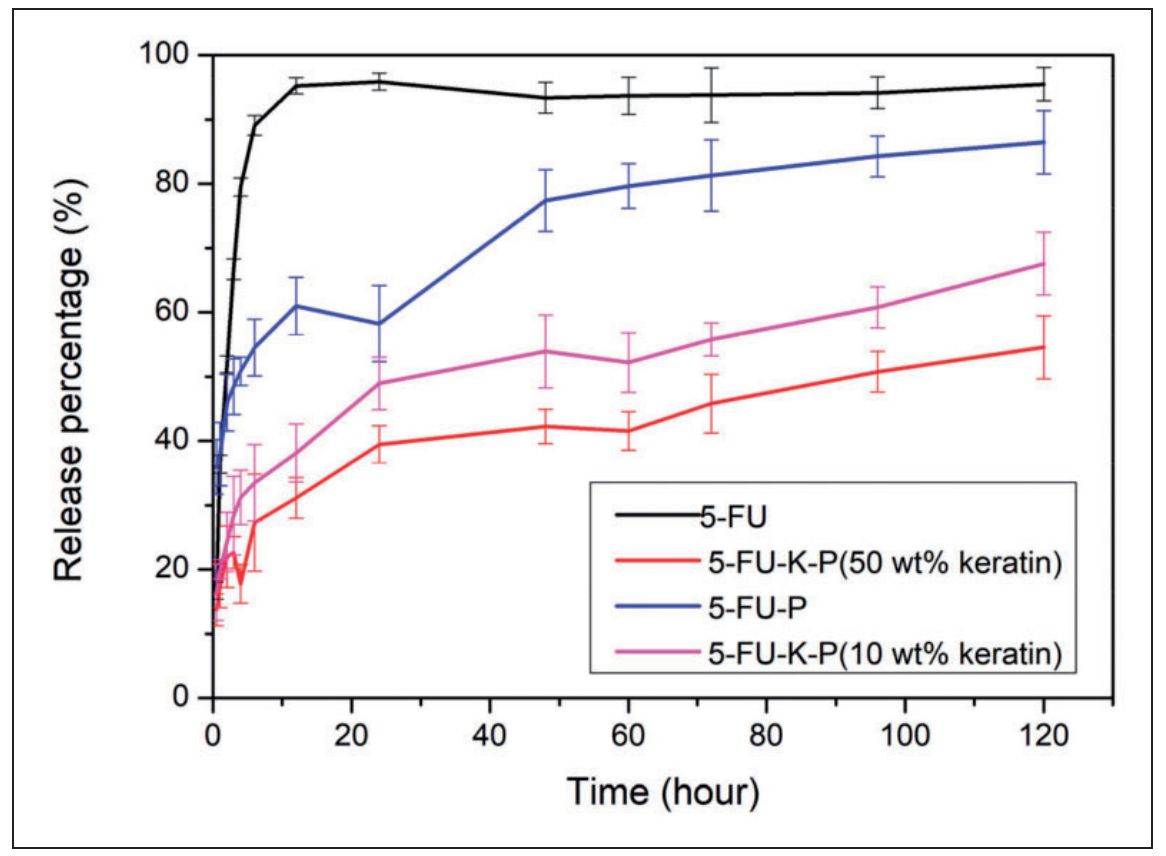

Figure 4. The controlled release profile of pure 5-FU, 5-FU-P, 5-FU-K-P(50wt\% keratin) and 5-FU-K-P( 10 wt $\%$ keratin $)$ nanofibers in neutral PBS solution within $120 \mathrm{~h}$.

detected, which demonstrated that the drug molecules were dispersed evenly within the polymer layer at a molecular level. In fact, crystallinity was considered as an important factor when evaluating the mechanical strength, polymer biodegradation and cellular affinity. Due to the low surface free energy, the amorphous electrospun nanofibers can provide more cell attachments and be helpful for tissue growth, compared with the crystalline materials. Therefore, it is desirable to select the amorphous materials for biomaterials.

\section{Drug release profile and the release kinetics}

The in vitro release profiles of 5-FU loaded PLLA nanofibers and PLLA nanofibers with keratin at a temperature of $37^{\circ} \mathrm{C}$ in the phosphate buffer solutions (pH 7.4) are shown in Figure 4. The weight ratios of 5-FU were the same for all nanofibers during the releasing experiments. The variable in the experiment is the weight ratio of keratin. For 5-FU-P nanofibers, more than $57 \%$ 5-FU was released within the first $24 \mathrm{~h}$. Its poor controlled release performance was due to the lack of keratin. In contrast, a significant sustained release curve was observed from 5-FU-K-P(50 wt $\%$ keratin) nanofibers. Only 35\% 5-FU was released from 5-FU$\mathrm{K}-\mathrm{P}(50 \mathrm{wt} \%$ keratin $)$ nanofibers in $24 \mathrm{~h}$ and the cumulative release rate gradually decreased until $120 \mathrm{~h}$. The cumulative release rate of 5-FU-K-P with low keratin weight ratio did not slow down significantly. The results indicated that with more keratin in the composite nanofibers, a clearer sustained release of 5-FU can be achieved. However, there is a maximum weight ratio of keratin in the composite nanofibers. When the weight ratio of keratin is larger than $60 \%$, more keratin aggregation beads, which severely influence the release performance, can be observed. Therefore, 5-FU-K$\mathrm{P}(50 \mathrm{wt} \%$ keratin $)$ nanofibers were selected for the $\mathrm{pH}$ sensitivity evaluation.

To investigate the mechanism of 5-FU and keratin released from composite nanofibers, the release curve of 5-FU-P nanofibers and 5-FU-K-P nanofibers were fitted to the Korsmeyer-Peppas kinetic model. As shown in Table 1 , the regression coefficient $\left(\mathrm{R}^{2}\right)$ and release constant $(\mathrm{k})$ values were obtained. The values of $\mathrm{R}^{2}$ of 0.9731 and 0.9671 indicated that the drug release performance was mainly controlled by diffusion; $\mathrm{k}$ values decreased from 39.78 to 16.83 with the introduction of keratin into the tetra-component nanofibers. In addition, the values of $\mathrm{n}$ for 5-FU-P nanofibers and 5FU-K-P nanofibers were both below 0.45 , indicating the release mechanism as a typical Fickian diffusion.

\section{Kinetics exploration of the interaction between 5-FU and keratin precipitates}

Zeta potential is an important parameter for evaluating the stability of nanoparticles and the charges on the surface of colloids. Hence it is introduced to characterize the charge interactions between keratin and 5-FU. The zeta potential is defined as the potential difference between bulk solution and the shear plane via movement of the particle in the solution. The positive or 
negative value of zeta potential represented the more stable particles due to electrical repulsion. ${ }^{39}$ As shown in Figure 5(a), the zeta potential of keratin precipitates was $-12.72 \pm 2.72 \mathrm{mV}$. This indicated that keratin colloids were stable with negative-charge surface. The negative charges were mainly from the carboxymethyl keratin. However, a significant shift can be observed after adding 5-FU into the composite system. As shown in Figure 5(b), the zeta potential of 5-FU/keratin composites changed to almost $0 \mathrm{mV}$ which indicated an unstable colloids system. The terminal of keratin possessed $-\mathrm{NH}_{3}{ }^{+}$group with positive charge. Because of the electrostatic interaction that occurs between $\mathrm{NH}_{3}{ }^{+}$group and $\mathrm{F}^{-}$group of 5-FU, tracking the variation in the micro-carrier surface zeta potential can indicate the kinetics of interaction between keratin polypeptides and 5-FU. Besides the electrostatic attraction, 5-FU could also react with the keratin polypeptides with cysteine residue. As described in Scheme 1, as an electron-rich group, the thiol group of cysteine residue can attack $\alpha$-carbon atoms which are linked to some strong electronegativity groups, for example, the fluoride atom in Scheme 1. Then the $\mathrm{S}-\mathrm{C}$ bond was formed and the $\mathrm{F}$ atom was substituted by the thiol group of cysteine.

\section{pH-sensitivity of drug-loaded nanofibers}

As shown in Figure 6, a series of controlled release experiments indicated the $\mathrm{pH}$ sensitivity of the

Table I. Fitting results for the data of sustained release curves

\begin{tabular}{rlll}
\hline & $R^{2}$ & $k$ & $n$ \\
\hline $5-F U-P$ & 0.9731 & 39.77 & 0.1639 \\
$5-F U-K-P$ & 0.9671 & 16.83 & 0.2395 \\
\hline
\end{tabular}

composite nanofibers. The 5-FU-P nanofibers and 5FU-K-P nanofibers were both examined at $\mathrm{pH} 7.4$, which mimics the healthy cells environment, and $\mathrm{pH}$ 6.0, which mimics the tumor cells environment. A burst release could be observed for all samples in the first $10 \mathrm{~h}$. For 5-FU-P nanofibers, releasing difference can hardly be observed in the neutral environment and acidic environment. After $70 \mathrm{~h}$ releasing period, more than $80 \%$ 5-FU was dismissed from both pH 7.4 PBS and $\mathrm{pH}$ 6.0 PBS solutions. However, for the samples of 5-FU-K-P, a significant difference in 5-FU release profiles can be observed in different $\mathrm{pH}$ environments. In the acidic PBS solution, 5-FU-K-P dismissed 50\% 5$\mathrm{FU}$ in the first $50 \mathrm{~h}$ with sustained release of $82 \% 5-\mathrm{FU}$ till the end of $120 \mathrm{~h}$. In contrast, only $40 \%$ of the loaded amount was released at the end of $120 \mathrm{~h}$ in the neutral environment. This $\mathrm{pH}$ sensitivity indicated that the 5FU-K-P nanofibers can be a preferable drug release carrier for clinical applications. For local chemotherapy, it is desirable that sufficient amount of antitumor drugs are released rapidly and accurately to eliminate the cancer cells at the targeted tissue site, while a smaller amount of drugs are released to the surrounding normal tissue to protect healthy cells from the side effect of antitumor drugs. The $\mathrm{pH}$ value variation is an ideal trigger factor for the selective release of anticancer drugs in local tumor chemotherapy. The nanofibers in the present study are sensitive to the changes of $\mathrm{pH}$ values, which can be utilized widely in the area of antitumor treatment.

\section{The cell uptake assay}

The fluorescence images revealed the cells take-up performances and proliferation performances on various nanofibrous surfaces. As shown in Figure 7, four groups of samples were tested for $120 \mathrm{~h}$ : PLLA nanofibers, keratin/PLLA nanofibers, 5-FU-P nanofibers and

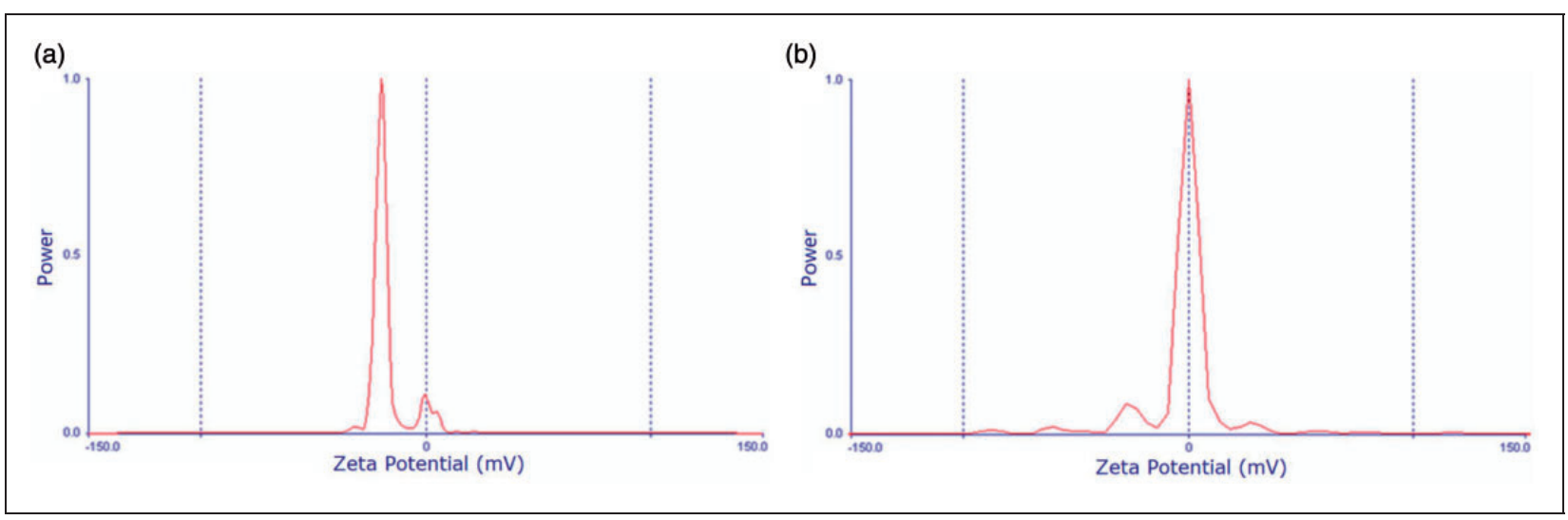

Figure 5. The zeta potential results of (a) pure keratin and (b) 5-FU-keratin composites. 


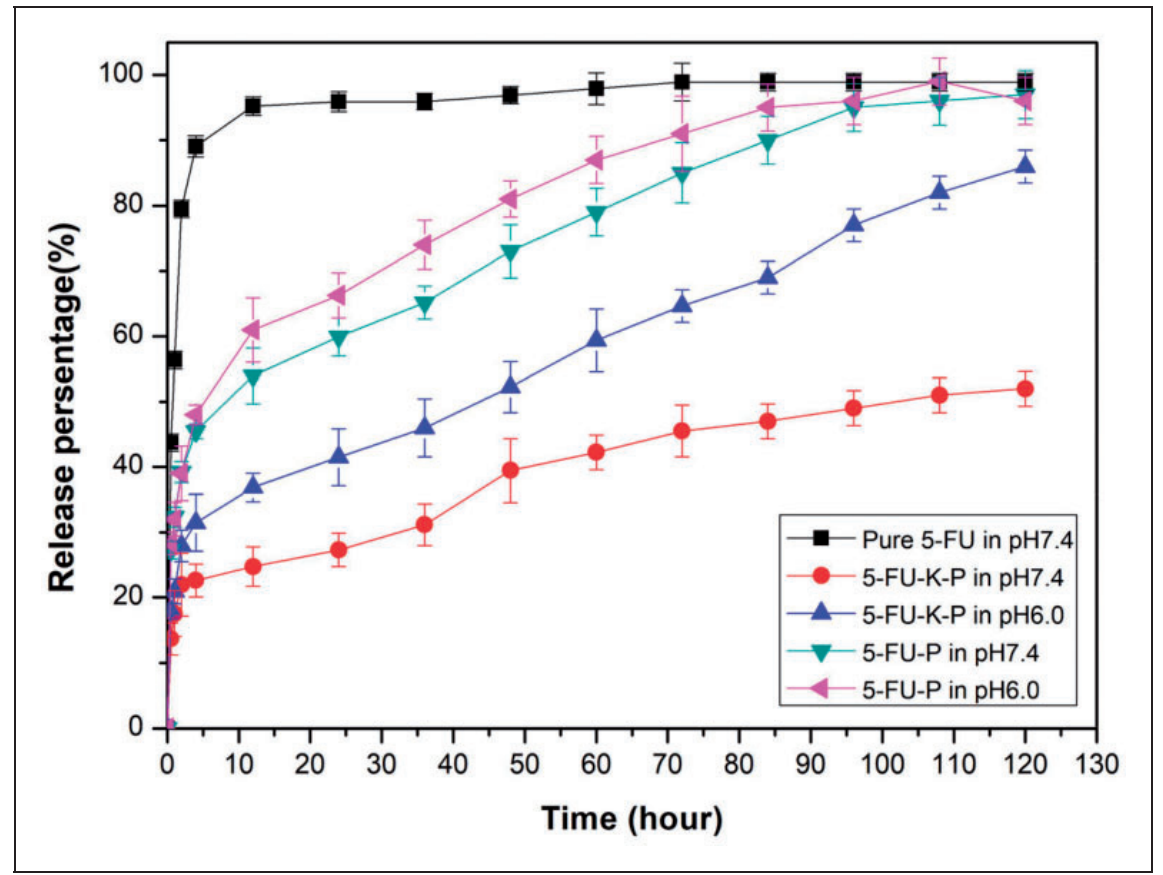

Figure 6. The drug release profiles of 5-FU-P and 5-FU-K-P nanofibers at different $\mathrm{pH}$ environments.

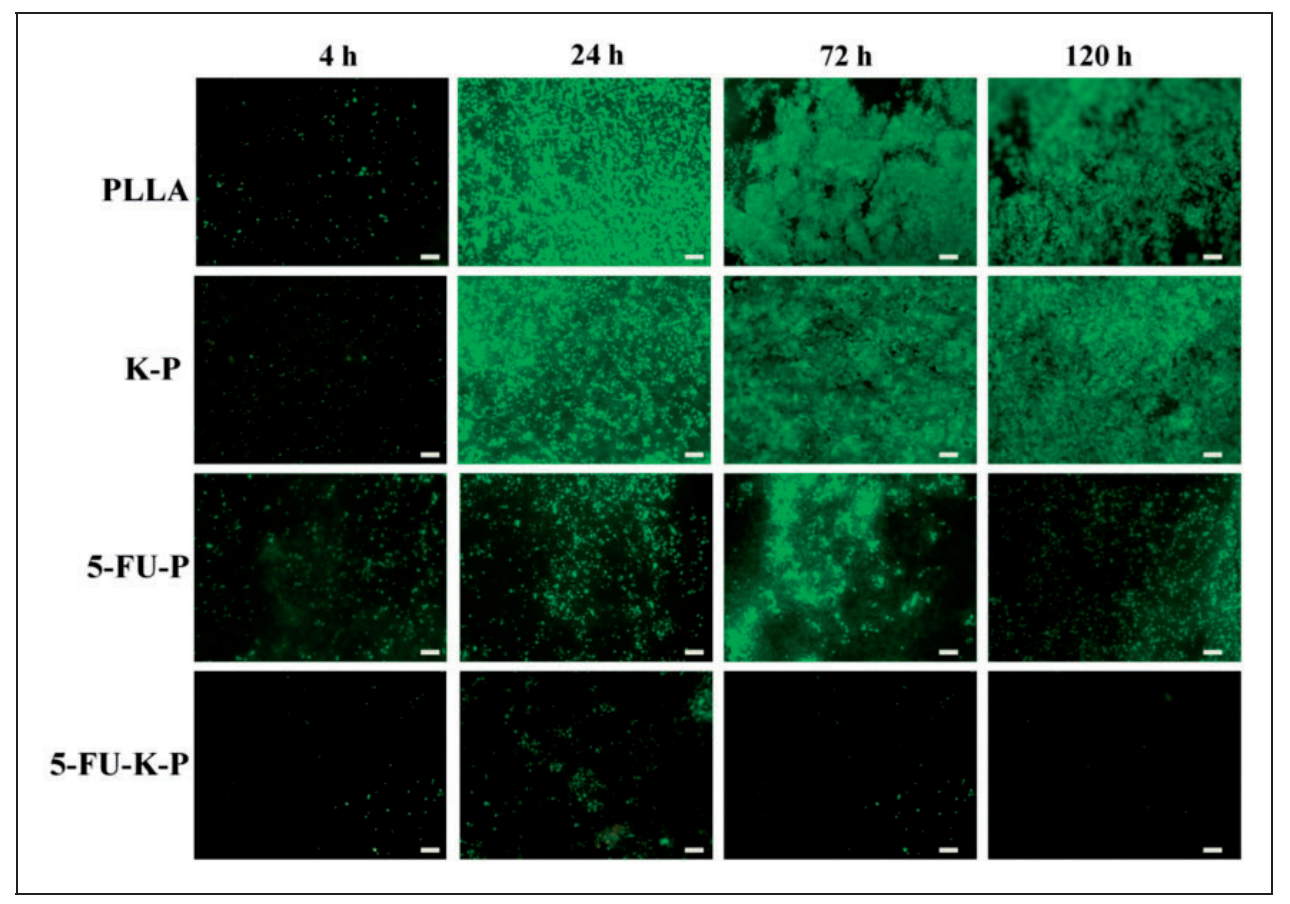

Figure 7. The fluorescence microscopy images of HCT-II6 cells for incubation with 5-FU released media at $4 \mathrm{~h}, 24 \mathrm{~h}, 72 \mathrm{~h}$ and 120 h. (The scale bar in the image is $100 \mu \mathrm{m}$.)

PLLA: poly(L-lactide).

5-FU-K-P nanofibers. The pure PLLA sample was applied as a control. Figure 7 shows the images of 5FU taken at $4 \mathrm{~h}, 24 \mathrm{~h}, 72 \mathrm{~h}$ and $120 \mathrm{~h}$. Pure PLLA nanofibers displayed a preferable environment for tumor cells. However, after adding 5-FU into the nanofibers, 5 -FU-P showed the antitumor effect in the first $24 \mathrm{~h}$. Then its antitumor effect decreased gradually due to the poor controlled-release performance of 5-FU-P 


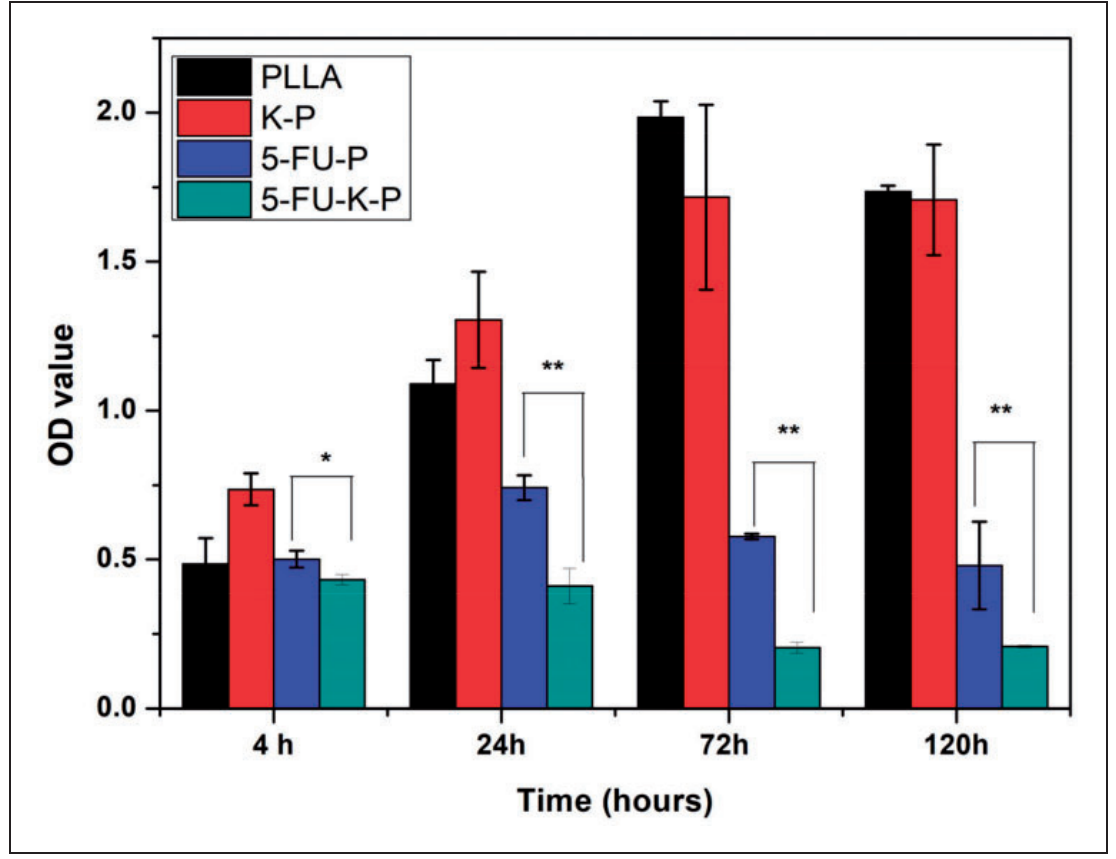

Figure 8. MTS assay of HCT-II 6 viability on different nanofiber surfaces $\left({ }^{*} p<0.05 ;{ }^{*} p<0.0 \mathrm{I}\right)$. PLLA: poly(L-lactide); OD: II. [AQ11]

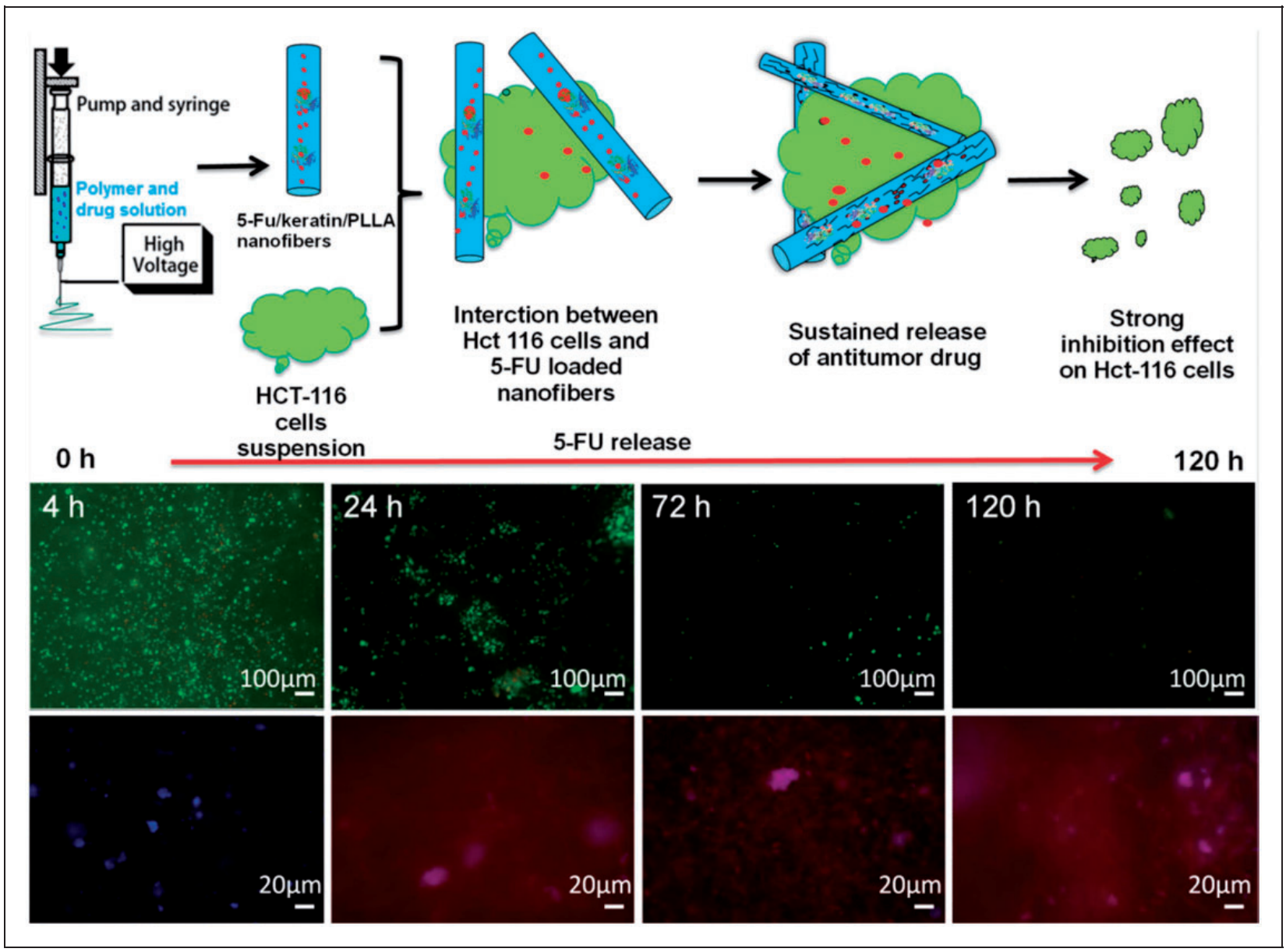

Figure 9. Schematic representation of interaction between tumor cells and 5-FU-K-P nanofibers. PLLA: poly(L-lactide). 


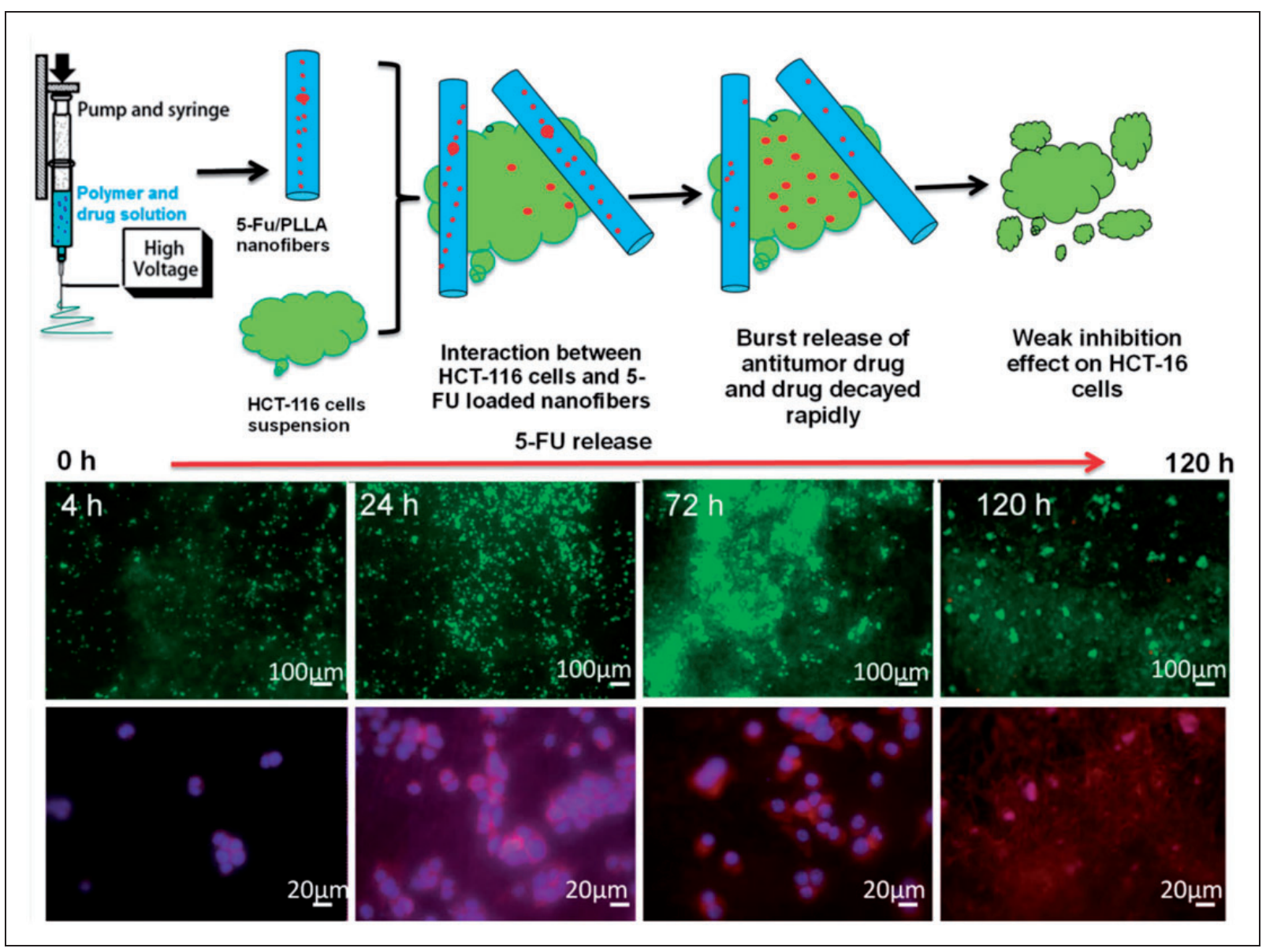

Figure 10. Schematic representation of interaction between tumor cells and 5-FU-P nanofibers. PLLA: poly(L-lactide).

nanofibers. In contrast, it can be seen that 5-FU-K-P nanofibers achieved significant sustained-release of 5FU up to $120 \mathrm{~h}$. The results demonstrated that keratin played an important role in controlling release of 5-FU and inhibiting the proliferation of HCT-116 cells.

\section{Cytotoxicity test by MTS assay}

The cellular toxicity effect was evaluated by MTS assay. As shown in Figure 8, comparisons among four composite nanofibers can be seen. Statistical analysis revealed a difference between 5-FU-P nanofibers and the 5-FU-K-P nanofibers on the viability of HCT-116 cells. After incubation periods of $120 \mathrm{~h}$, PLLA nanofibers and K-P nanofibers possessed better cytocompatibility compared with other nanofibers. Both 5-FU-P nanofibers and 5-FU-K-P nanofibers displayed significant antitumor inhibition effects on HCT-116 cells. In the first $4 \mathrm{~h}$, the difference in cell viability between 5FU-P nanofibers and 5-FU-K-P nanofibers was not significant. However, after incubation for $24 \mathrm{~h}$, the difference was further enlarged. The function of keratin was designed to achieve the controlled-release of 5-FU since 5-FU is easily released and rapidly decayed with a short half-life in plasma. The results indicated that after adding keratin there was a significant controlled release effect on 5-FU release profile.

The antitumor mechanisms of 5-FU-K-P nanofibers and 5-FU-P nanofibers are explicated in Figure 9 and Figure 10, respectively. The function of keratin was to achieve the controlled-release of 5-FU for local chemotherapy. Due to the side effect of 5-FU on normal cells, it is desired that a higher dose of drug can be released focusing at the tumor site, while the minimum dose of drug is released near tumor site to protect the healthy cells from the chemotherapeutic drug. When HCT-116 cells attach on the surface of 5-FU-P nanofibers, a burst-release occurs due to its lack of controlledrelease components and the healthy cells near the sites can be damaged by excessive exposure to a high concentration of antitumor drug. After the burst release, 5-FU decayed rapidly in the environment and its antitumor function was hindered thereafter. Therefore it is necessary to introduce keratin into the nanofibers, 
which can buffer the fluctuation of the drug concentration. It can eliminate the burst release phenomenon for embedding 5-FU molecules with charge interaction. Also keratin can slow down the drug degradation rate in plasma by sustainable release.

\section{Conclusion}

The abundant functional groups in keratin suggest that it can be utilized for the conjugation with chemotherapeutic drugs for tumor-specific release. Moreover, the different amino acid terminals of keratin indicated its $\mathrm{pH}$-sensitivity. In the present work, novel $\mathrm{pH}$-triggered keratin-based composite nanofibers were designed for local tumor chemotherapy. The composite nanofibers were fabricated by electrospinning technology. The morphology of nanofibers was investigated by SEM. The SEM images indicated the mean diameters of the nanofibers decreased from $1.88 \pm 0.05 \mu \mathrm{m}$ to $0.81 \pm 0.03 \mu \mathrm{m}$ with a lower polymer concentration. All nanofibers possessed homogeneous and superfine structures without beads. The FTIR spectra indicated the chemical structures of keratin and 5-FU were maintained after the process of electrospinning. The TGA and DTG spectra demonstrated stable thermal stability of the composite nanofibers. The XRD analysis indicated that 5-FU molecules were homogeneously dispersed within the keratin and PLLA layer at a molecular level without crystalline structure. In addition, 5-FU-K-P nanofibers exhibited significant $\mathrm{pH}$-sensitive features. In the acidic environment, $83 \%$ 5-FU was released in $120 \mathrm{~h}$ while only $42 \%$ 5 -FU was released in the neutral environment. The cell cytotoxicity test indicated that 5-FU-K-P nanofibers exhibited an enhanced antitumor efficiency. Cell uptake assay suggested that 5-FU released from the 5-FU-K-P nanofibers was endocytosed by the tumor cells. The results of the present study shed light onto the potential localized antitumor activity of natural protein-based nanofibers and these composite nanofibers are a promising candidate material for clinical application.

\section{Acknowledgments}

The authors acknowledge Science and Technology Project of Shaanxi, China (Grant No: 2017JQ2006); the youth talent promotion plan of Shaanxi Association for science and technology (Grant No: 20190305).

\section{Declaration of conflicting interests}

The authors declared no potential conflicts of interest with respect to the research, authorship, and/or publication of this article.

\section{Funding}

The authors received no financial support for the research, authorship, and/or publication of this article.

\section{ORCID iD}

Jing Zhang (D) https://orcid.org/0000-0001-6503-2933

\section{References}

1. Binnewies M, Roberts EW, Kersten $\mathrm{K}$, et al. Understanding the tumor immune microenvironment (TIME) for effective therapy. Nat Med 2018; 24: 541-550.

2. Wettersten HI, Weis SM, Pathria P, et al. Arming tumorassociated macrophages to reverse epithelial cancer progression. Cancer Res 2019; 79: 5048-5059.

3. Kankala RK, Liu C-G, Yang D-Y, et al. Ultrasmall platinum nanoparticles enable deep tumor penetration and synergistic therapeutic abilities through free radical species-assisted catalysis to combat cancer multidrug resistance. Chem Eng 2020; 383: 123138.

4. Lim ZZJ, Li JEJ, Ng CT, et al. Gold nanoparticles in cancer therapy. Acta Pharmacol Sin 2011; 32: 983-990.

5. Ariyan CE, Brady MS, Siegelbaum RH, et al. Robust antitumor responses result from local chemotherapy and CTLA-4 blockade. Cancer Immunol Res 2018; 6: 189-200.

6. Kleckner IR, Kamen C, Gewandter JS, et al. Effects of exercise during chemotherapy on chemotherapy-induced peripheral neuropathy: a multicenter, randomized controlled trial. Support Care Cancer 2018; 26: 1019-1028.

7. O'Leary CE, Collins A, Henman MC, et al. Introduction of a dose-banding system for parenteral chemotherapy on a haematology-oncology day ward. J Oncol Pharm Pract 2019; 25: 351-361.

8. Riba LA, Gruner RA, Fleishman A, et al. Surgical risk factors for the delayed initiation of adjuvant chemotherapy in breast cancer. Ann Surg Oncol 2018; 25: 1904-1911.

9. Liu W, Wei J, Wei Y, et al. Controlled dual drug release and in vitro cytotoxicity of electrospun poly (lactic-coglycolic acid) nanofibers encapsulated with micelles. J Biomed Nanotechnol 2015; 11: 428-435.

10. Ignatova MG, Manolova NE, Rashkov IB, et al. Poly (3hydroxybutyrate)/caffeic acid electrospun fibrous materials coated with polyelectrolyte complex and their antibacterial activity and in vitro antitumor effect against HeLa cells. Mater Sci Eng C 2016; 65: 379-392.

11. Haidar MK and Eroglu H. Nanofibers: new insights for drug delivery and tissue engineering. Curr Top Med Chem 2017; 17: 1564-1579.

12. Li Q, Zhu L, Liu R, et al. Biological stimuli responsive drug carriers based on keratin for triggerable drug delivery. J Mater Chem 2012; 22: 19964-19973.

13. Sağira T, Huysalb M, Durmusc Z, et al. Preparation and in vitro evaluation of 5-fluorouracil loaded magnetitezeolite nanocomposite (5-FU-MZNC) for cancer drug delivery applications. Biomed Pharmacother 2016; 77: 182-190.

14. Nagarwal RC, Kumar R and Pandit JK. Chitosan coated sodium alginate-chitosan nanoparticles loaded with 5FU for ocular delivery: In vitro characterization and in vivo study in rabbit eye. Eur J Pharm Sci 2012; 47: 678-685. 
15. Prabha $G$ and Raj V. Formation and characterization of $\beta$-cyclodextrin $(\beta$-CD) - polyethyleneglycol (PEG) polyethyleneimine (PEI) coated $\mathrm{Fe} 3 \mathrm{O} 4$ nanoparticles for loading and releasing 5-Fluorouracil drug. Biomed Pharmacother 2016; 80: 173-182.

16. Chunga T-W, Lind S-Y, Liub DZ, et al. Sustained release of 5-FU from Poloxamer gels interpenetrated by crosslinking chitosan network. Int J Pharm 2009; 382: 39-44.

17. Idris A, Vijayaraghavan R, Rana UA, et al. Dissolution of feather keratin in ionic liquids. Green Chem 2013; 15 : 525-534.

18. Choi J, Panthi G, Liu Y, et al. Keratin/poly (vinyl alcohol) blended nanofibers with high optical transmittance. Polymer 2015; 58: 146-152.

19. Dowling LM, Crewther WG and Parry DAD. Secondary structure of component $8 \mathrm{c}-1$ of $\alpha$-keratin. An analysis of the amino acid sequence. Biochem $J$ 1986; 236: 705-712.

20. Aluigi A, Zoccola M, Vineis C, et al. Study on the structure and properties of wool keratin regenerated from formic acid. Int J Biol Macromol 2007; 41: 266-273.

21. Zhang J, Li Y, Li J, et al. Isolation and characterization of biofunctional keratin particles extracted from wool wastes. Powder Technol 2013; 246: 356-362.

22. Katti DS, Robinson KW, Ko FK, et al. Bioresorbable nanofiber-based systems for wound healing and drug delivery: Optimization of fabrication parameters. J Biomed Mater Res B 2004; 70: 286-296.

23. Bhattarai SR, Bhattarai N, Yi HK, et al. Novel biodegradable electrospun membrane: Scaffold for tissue engineering. Biomaterials 2004; 25: 2595-2602.

24. Kim TG and Park TG. Surface functionalized electrospun biodegradable nanofibers for immobilization of bioactive molecules. Biotechnol Prog 2006; 22: 1108-1113.

25. Zhang J, Li Y, Li J, et al. Generation of biofunctional and biodegradable electrospun nanofibers composed of poly (l-lactic acid) and wool isoelectric precipitate. Text Res $J$ 2014; 84: 355-367.

26. Wang X, Lv F, Li T, et al. Correction to electrospun micropatterned nanocomposites incorporated with $\mathrm{Cu} 2 \mathrm{~S}$ nanoflowers for skin tumor therapy and wound healing. ACS Nano 2019; 13: 3740-3740.

27. Norouzi M. Recent advances in brain tumor therapy: application of electrospun nanofibers. Drug Discov Today 2018; 23: 912-919.
28. Wang M, Xiao Y, Lin L, et al. A microfluidic chip integrated with hyaluronic acid-functionalized electrospun chitosan nanofibers for specific capture and nondestructive release of CD44-overexpressing circulating tumor cells. Bioconjugate Chem 2018; 29: 1081-1090.

29. Radmansouri M, Bahmani E, Sarikhani E, et al. Doxorubicin hydrochloride-loaded electrospun chitosan/ cobalt ferrite/titanium oxide nanofibers for hyperthermic tumor cell treatment and controlled drug release. Int $J$ Biol Macromol 2018; 116: 378-384.

30. Li X, Yang Y, Fan Y, et al. Biocomposites reinforced by fibers or tubes as scaffolds for tissue engineering or regenerative medicine. J Biomed Mater Res A 2014; 102: 1580-1594.

31. Nair LS and Laurencin CT. Biodegradable polymers as biomaterials. Prog Polym Sci 2007; 32: 762-798.

32. Chen B-Q, Kankala RK, Chen A-Z, et al. Investigation of silk fibroin nanoparticle-decorated poly (1-lactic acid) composite scaffolds for osteoblast growth and differentiation. Int $J$ Nanomedicine 2017; 12: 1877.

33. Rasouli R, Barhoum A, Bechelany M, et al. Nanofibers for biomedical and healthcare applications. Macromol Biosci 2019; 19: 1800256.

34. Cai X, Luan Y, Dong Q, et al. Sustained release of 5fluorouracil by incorporation into sodium carboxymethylcellulose sub-micron fibers. Int J Pharm 2011; 419: 240-246.

35. El-Khoueiry AB and Lenz HJ. Should continuous infusion 5-fluorouracil become the standard of care in the USA as it is in Europe? Cancer Invest 2006; 24: 50-55.

36. Nistor MT, Chiriac AP, Nita LE, et al. Characterization of the semi-interpenetrated network based on collagen and poly(N-isopropyl acrylamide-co-diethylene glycol diacrylate). Int J Pharm 2013; 452: 92-101.

37. Chen SC, Huang XB, Cai XM, et al. The influence of fiber diameter of electrospun poly(lactic acid) on drug delivery. Fiber Polym 2012; 13: 1120-1125.

38. Zhang J, Li Y, Li J, et al. Generation of biofunctional and biodegradable electrospun nanofibers composed of poly (L-lactic acid) and wool isoelectric precipitate. Text Res J 2014; 84: 355-367.

39. Greenwood R. Review of the measurement of zeta potentials in concentrated aqueous suspensions using electroacoustics. Adv Colloid Interface Sci 2003; 106: 55-81. 